\title{
Use of ICT in Teacher Education
}

\author{
Mr. Parmanand Barodiya ${ }^{1}$, Mr. Saurveer Singh ${ }^{2}$, Mrs. Anupam Choudhary ${ }^{3}$
}

\section{ABSTRACT:}

Professional development to incorporate ICTs into teaching and learning is an ongoing process. Teacher education curriculum needs to update this knowledge and skills as the school curriculum change. The teachers need to learn to teach with digital technologies, even though many of them have not been taught to do so. The aim of teacher training in this regard can be either teacher education in ICTs or teacher education through ICTs. A teacher's professional development is central to the overall change process in education. In planning the integration of technology in Teacher education it is important for teacher education, Institution to understand the knowledge and skills necessary for teachers to effectively use ICT in their instructions. Teachers need technical assistance to use and maintain technology. In this paper discuses to study of Teacher education, to know the Significance of ICT in teacher education and to provide the some Suggestions of teacher education.

Keywords: Teacher education, ICT, E-Learning, Information and communications technologies.

The information society challenges the education system. In recent years, the speedy, effective and global communication of knowledge has created a new foundation for co-operation and teamwork, both nationally and internationally. The increasing role played by information technology in the development of society calls for an active reaction to the challenges of the information society.

In the report of UNESCO (1996) learning 'the world comes into the Classroom'. Teacher education has additionally to inculcate view of teaching that transcends the utilitarian and encourages for global competition one of the main functions of teacher education. The more appropriate approaches is being mentioned as follows:

ICT - Information and communications technologies [ICT] has been instrumental in social transformations.

E-Learning - It is an approach to facilitate and enhance learning through the use of devices based on both computer and communication technologies. E - Learning can also be used to support distance learning.

\section{$1,2,3$ Lecturer of Education Dept. Preston College, Gwalior (MP)}

(C) 2015 I P Barodiya, S Singh, A Choudhary; licensee IJIP. This is an Open Access Research distributed under the terms of the Creative Commons Attribution License (http://creativecommons.org/licenses/by/2.0), which permits unrestricted use, distribution, and reproduction in any Medium, provided the original work is properly cited. 
Computer Assisted Learning [CAL] - CAL is often used to create 'models' for experimental purpose Using CAL programmes, the student are provided with an opportunity to carry our experiments.

Learning with Multimedia - The multimedia has potential to change traditional educational methods. It will help teacher to represent in a more meaningful way with using different media effective as compare with traditional method of teaching. This is an age where in the world comes into the classroom and with this the expectations and responsibilities of teachers are seemingly limitless. An effort for updating their knowledge and skill with the help of information technology, and inculcation of social and ethical values is necessary.

\section{OBJECTIVE}

- To study of Teacher education.

- To know the Significance of IT in teacher education.

- To provide the some Suggestions of teacher education.

\section{RESEARCH METHODOLOGY}

The researchers have adopted descriptive methodology for this study Research has been placed on secondary data sources such as books, journals, newspapers and online database.

\section{Teacher Education}

Teacher education refers to the policies and procedures designed to equip teachers with the knowledge, attitudes, behaviors, and skills they require to perform their tasks effectively in the school and classroom. In early times, teachers were often scholars or clergymen who had no formal training in how to teach the subjects of their expertise. In fact, many believed that "teachers were born, not made." It was not until the emergence of pedagogy, the "art and science of teaching," as an accepted discipline that the training of teachers was considered important. Although there has been continued debate about whether teaching is a "science" that can be taught or whether one is "born" to be a teacher, it has generally been agreed, at least since the nineteenth century, that certain characteristics are needed to qualify a person as a teacher knowledge of the subject matter to be taught, knowledge of teaching methods, and practical experience in applying both. Most educational programs for teachers today focus upon these points. However, the internal character of the individual is also an important aspect of teaching; whether that is something one is born with or can be taught, and what are the qualities that are needed for the role of teacher, are also a matter of debate.

\section{Definition of ICT}

Most participants agreed that "anything used to transform knowledge," both software and hardware should be counted as ICT. One participant stated that "all is technology." However, this omnipresence of technology is not without problems. The participants used statements like, "it exists just to be there" and "it is here but it is not there," to express frustration with ICT not being actually used in schools in which they did practice teaching. 


\section{ICTs in Teacher Education}

Professional development to incorporate ICTs into teaching and learning is an ongoing process. Teacher education curriculum needs to update this knowledge and skills as the school curriculum change. The teachers need to learn to teach with digital technologies, even though many of them have not been taught to do so. The aim of teacher training in this regard can be either teacher education in ICTs or teacher education through ICTs. A teacher's professional development is central to the overall change process in education. They are unsure of how to make most effective use of ICT as a powerful and diverse resource and one which can potentially alter traditional teacher-student relationships. If they are to invest time and energy in embracing the technology, teachers need to understand and experience the potential benefits of using ICT. Moreover, they need to have access to the evidence that supports the improvements in teaching and learning, including case studies and examples of effective practice. If the necessary changes in education are to be realized, they need strong leadership and support along with a school development plan for the integration of technology. They also need technical support so that they feel comfortable in using the technology and are more willing to experiment. The Future lab study shows many affirmative results from review of a number of UK case studies on teacher training. Although they are not representative, most of these studies highlight positive impacts of teacher training with ICT, such as increasing teacher self-assurance and aptitude in the use of IT resources by providing them fully equipped multimedia portable computers (MPTP) or by supporting online teacher communities. The "Talking Heads Online Community" pilot study showed that informal online communities can help to reduce head teacher isolation, enable head teachers to generate and exchange insights regarding practices for school improvement, and provide an effective way for gaining quick access to a spectrum of perspectives on key topical issues.

\section{SIGNIFICANCE OF IT IN TEACHER EDUCATION}

- Access to variety of learning resources: In the era of technology. IT aids plenty of resources to enhance the teaching skills and learning ability. With the help of IT now it is easy to provide audio visual education. The learning resources are being widens and widen. Now with this vivid and vast technique as part of the IT curriculum, learners are encouraged to regard computers as tools to be used in all aspects of their studies. In particular, they need to make use of the new multimedia technologies to communicate ideas, describe projects, and order information in their work.

- Immediacy to information: IT has provided immediacy to education. Now in the year of computers and web networks the pace of imparting knowledge is very fast and one can be educated anywhere at any time. New IT has often been introduced into well-established patterns of working and living without radically altering them. For example, the traditional office, with secretaries working at keyboards and notes being written on paper and manually exchanged, has remained remarkably stable, even if personal computers have replaced typewriters. 
- Any time learning: Now in the year of computers and web networks the pace of imparting knowledge is very fast and one can be educated .One can study whenever he wills irrespective of whether it is day or night and irrespective of being in India or in US because of the boom in IT.

- Collaborative learning: Now IT has made it easy to study as well as teach in groups or in clusters. With online we can be unite together to do the desired task. Efficient postal systems, the telephone (fixed and mobile), and various recording and playback systems based on computer technology all have a part to play in educational broadcasting in the new millennium. The Internet and its Web sites are now familiar to many children in developed countries and among educational elites elsewhere, but it remains of little significance to very many more, who lack the most basic means for subsistence.

- Multimedia approach to education: Audio-Visual Education, planning, preparation, and use of devices and materials that involve sight, sound, or both, for educational purposes. Among the devices used are still and motion pictures, filmstrips, television, transparencies, audiotapes, records, teaching machines, computers, and videodiscs. The growth of audiovisual education has reflected developments in both technology and learning theory. Studies in the psychology of learning suggest that the use of audio-visuals in education has several advantages. All learning is based on perception, the process by which the senses gain information from the environment. The higher processes of memory and concept formation cannot occur without prior perception. People can attend to only a limited amount of information at a time; their selection and perception of information is influenced by past experiences. Researchers have found that, other conditions being equal, more information is taken in if it is received simultaneously in two modalities (vision and hearing, for example) rather than in a single modality. Furthermore, learning is enhanced when material is organized and that organization is evident to the student.

- Authentic and up to date information: The information and data which are available on the net is purely correct and up to date. Internet, a collection of computer networks that operate to common standards and enable the computers and the programs they run to communicate directly provides true and correct information.

- Online library: Internets support thousands of different kinds of operational and experimental services one of which is online library. We can get plenty of data on this online library. As part of the IT curriculum, learners are encouraged to regard computers as tools to be used in all aspects of their studies. In particular, they need to make use of the new multimedia technologies to communicate ideas, describe projects, and order information in their work. This requires them to select the medium best suited to conveying their message, to structure information in a hierarchical manner, and to link together information to produce a multidimensional document.

- Distance learning: Distance Learning, method of learning at a distance rather than in a classroom. Late 20th-century communications technologies, in their most recent phases multimedia and interactive, open up new possibilities, both individual and institutional, for an unprecedented expansion of home-based learning, much of it part-time. The term distance 
learning was coined within the context of a continuing communications revolution, largely replacing a hitherto confusing mixed nomenclature - home study, independent study, external study, and, most common, though restricted in pedagogic means, correspondence study. The convergence of increased demand for access to educational facilities and innovative communications technology has been increasingly exploited in face of criticisms that distance learning is an inadequate substitute for learning alongside others in formal institutions. A powerful incentive has been reduced costs per student. At the same time, students studying at home themselves save on travel time and other costs.

- Better accesses to children with disabilities: Information technology has brought drastic changes in the life of disabled children. IT provides various software and technique to educate these poor peoples. Unless provided early with special training, people profoundly deaf from birth are incapable of learning to speak. Deafness from birth causes severe sensory deprivation, which can seriously affect a person's intellectual capacity or ability to learn. A child who sustains a hearing loss early in life may lack the language stimulation experienced by children who can hear. The critical period for neurological plasticity is up to age seven. Failure of acoustic sensory input during this period results in failure of formation of synaptic connections and, possibly, an irremediable situation for the child. A delay in learning language may cause a deaf child's academic progress to be slower than that of hearing children. The academic lag tends to be cumulative, so that a deaf adolescent may be four or more academic years behind his or her hearing peers. Deaf children who receive early language stimulation through sign language, however, generally achieve academically alongside their hearing peers. The integration of information technology in teaching is a central matter in ensuring quality in the educational system. There are two equally important reasons for integrating information technology in teaching. Pupils must become familiar with the use of information technology, since all jobs in the society of the future will be dependent on it, and information technology must be used in teaching in order to improve its quality and make it more effective.

\section{SUGGESTIONS}

Some suggestion for new approaches in teacher education:-

- New methods' like Research, experiments, project discussion, problem solving should be used more and more.

- With the use of ICT in teaching method teacher should create direct connection to student learning and its goal is to improve student achievement.

- Teacher not remains merely lecturers or instructors but they should play the new roles of teachers as facilitators and guides. Use of technology in methods can speed up the efficiency of instructional tasks.

- Thus it is desirable to search for ways in which knowledge can be share more effectively. To fulfill the need and aspiration the society these innovative ideas should be introduced in teaching methods. 


\section{CONCLUSION}

Overall, the study Each Teacher Education institution should be provided computer and other adequate infrastructure. Administration support for utilization of new technologies. Teachers and schools face a range of challenges, including infrastructural issues such as lack of power, telephone and Internet access, which hinder the effective use of ICT in teaching and learning. Schools also struggle to optimize use of the technology, due to a lack of appropriate professional development. While many teachers have developed basic computer skills, they have not yet become confident in using the technology to improve their own productivity and bring about pedagogical change. At the same time, ICT administrators and principals are requesting more support in technology management and organizational integration of ICT. Such support is needed in order to align the aims of ICT initiatives with overall school development objectives.

\section{REFERENCES}

Kumari N.Kalpana (2012) Modern And Innovative Practices And Impact On Teacher Education, international Journal Of Multidisciplinary Educational Research ISSN: 22777881 Volume 1, Issue 2, June 2012

Singh Gajpal (2014) Emerging Trends and Innovations in Teacher Education, Volume : 4 | Issue : 5 | May 2014 | ISSN - 2249-555X

Gupta dr. nishi integration of technology in Teacher Education,(2012) dept.of edu.CSM university, Kanpur pp27

Curriculum Framework for Quality Teacher Education by NCTE retrieved from http:// www.ncte-india.org/pub/curr/curr_0.htm |

Naseem, S. and Anas, N.(201 I) Problems Of teacher Education In India, International Referred Research Journal, 2, 19, 187-188April. |

Sharma,G(2012) ' ICTs’ in Teacher Education, Review of Research, 1, 10, 1-4, July. |

\section{Webs}

- http://occupytheory.org/advantages-and-disadvantages-of-technology-in-education/

- http://www.teindia.nic.in/files/books_te/412_35a.pdf

- http://www.ed.gov/oii-news/use-technology-teaching-and-learning

- http://www.educationworld.com/a_tech/tech/tech004.shtml

- $\quad$ www.csi-india.org

- www.google.com 